\title{
Thermally stable, oxidation resistant capping technology for Ti/Al ohmic contacts to $n$-GaN
}

\author{
Christopher M. Pelto a) and Y. Austin Chang \\ Materials Science Program, University of Wisconsin-Madison, Madison, Wisconsin 53706 \\ Yong Chen and R. Stanley Williams \\ Quantum Science Research, Hewlett-Packard Laboratories, Palo Alto, California 94304
}

(Received 10 May 2002; accepted for publication 23 July 2002)

\begin{abstract}
The intermetallic $\mathrm{TiAl}_{3}$ has been used as a thermally stable cap for Ti/Al ohmic contacts to $n$-GaN. The electrical performance of the $\mathrm{TiAl}_{3}$-capped contact is nearly the same as that of a standard $\mathrm{Ti} / \mathrm{Al} / \mathrm{Ni} / \mathrm{Au}$ contact processed on the same substrate, but the $\mathrm{Ti} / \mathrm{Al} / \mathrm{TiAl}{ }_{3}$ contact's performance is optimized at a much lower temperature. The Ti/Al/TiAl ${ }_{3}$ contact achieved a lowest specific contact resistance ( $\left.\rho_{c}\right)$ of $2.1 \times 10^{-5} \Omega \mathrm{cm}^{2}$ following $1 \mathrm{~min}$ at $700^{\circ} \mathrm{C}$ in flowing, oxygen-gettered ultrahigh purity (UHP) Ar. The Ti/Al/Ni/Au contact standard achieved a $\rho_{c}$ of $1.8 \times 10^{-5} \Omega \mathrm{cm}^{2}$ following a $15 \mathrm{~s}$ anneal at $900^{\circ} \mathrm{C}$ in flowing, oxygen-gettered UHP Ar. The $\mathrm{TiAl}_{3}$-capped contact structure shows little sensitivity to the amount of oxygen in the annealing ambient for optimization, and we found that it could achieve a $\rho_{c}$ of $1.1 \times 10^{-5} \Omega \mathrm{cm}^{2}$ following $5 \mathrm{~min}$ at $600{ }^{\circ} \mathrm{C}$ in air. This performance is almost identical to that attained when the contact was annealed in oxygen-gettered UHP Ar and ordinary Ar. Anneals were extended to a total time of $20 \mathrm{~min}$ in the three ambient atmospheres, and the Ti/Al/ $\mathrm{TiAl}_{3}$ contact showed no significant difference in its performance. The fact that this contact structure can withstand optimization anneals in air suggests that it could be annealed alongside a $\mathrm{Ni} / \mathrm{Au}$ contact to $p-\mathrm{GaN}$ in air and still achieve a low contact resistance. The performance of the $\mathrm{TiAl}_{3}$-capped bilayer was found to be stable following thermal aging for more than $100 \mathrm{~h}$ at $350^{\circ} \mathrm{C}$ in air, which was also comparable to an optimally annealed $\mathrm{Ti} / \mathrm{Al} / \mathrm{Ni} / \mathrm{Au}$ contact aged at the same time. The $\mathrm{TiAl}_{3}$ material should be an oxidation cap solution for many other Ti/Al contact structures, almost regardless of the Ti:Al layer thickness ratio, since the $\mathrm{TiAl}_{3}$ will be stable on the upper Al layer. Use of this cap eliminates the need to alter a previously optimized bilayer, thus it is a means of enhancing any existing Ti/Al bilayer contact's performance without necessitating the reoptimization of the layers to accommodate the cap. (C) 2002 American Institute of Physics. [DOI: 10.1063/1.1507809]
\end{abstract}

\section{INTRODUCTION}

There is no question that $\mathrm{GaN}$ has generated a considerable amount of excitement among researchers in the last decade. The reason is obvious, given the significant potential of this wide band gap material to applications involving short wavelength optical devices ${ }^{1-3}$ and high temperature/high power electronic devices. ${ }^{4,5}$ As with any technology, though, implementation challenges exist. Among them, it has been difficult to find suitable low resistance contacts to $n$-type and especially $p$-type $\mathrm{GaN}$ that meet all of the requirements that the devices demand. The $n$-GaN ohmic contact hurdle was predominantly overcome with the development of the Ti/Al bilayer contact structure, where the Ti is deposited first on the $n$-GaN substrate. ${ }^{6}$ (It should be noted that it is common to list the layers of a multilayer such that the first layer deposited appears first in the contact name, followed by the subsequent layers in the order they were deposited, i.e., Ti is deposited as the first layer and Al the second in a Ti/Al contact.) Researchers immediately recognized that this con-

a) Author to whom correspondence should be addressed; electronic mail: pelto@cae.wisc.edu tact offered the first viable solution to the problem of ohmic contacts to $n$-GaN, which is evidenced by the amount of scrutiny that it received within the first few years to determine why it was so successful. ${ }^{7-10}$ Most subsequent ohmic contacts for this material involve this structure in some way. If annealing temperatures below $800^{\circ} \mathrm{C}$ are desired, we have found that the best specific contact resistance $\left(\rho_{c}\right)$ will be obtained when the Ti:Al layer thickness ratio is approximately $1: 3{ }^{11}$ The optimum layer thickness ratio obviously suggests that there is a preferred Ti:Al atomic ratio for the contact. Other groups have found a similar result when studying different layer thickness ratios for the Ti/Al contact. $^{12}$

Precise and well-controlled thermal processing is essential to realizing the full potential of the Ti/Al structure, which is demonstrated by the observation that the oxygen present in the annealing ambient can have a detrimental effect on the resulting electrical properties of the contact. ${ }^{11}$ In fact, it has been noted that most of the degradation of the specific contact resistance is due to the dramatic increase in the metal's resistance. ${ }^{12-14}$ Researchers have investigated several modifications to improve the Ti/Al contact. Wu et al. added a second Ti/Al layer once the original Ti/Al bilayer had been 
annealed in order to decrease the metal film's sheet resistance. ${ }^{15}$ This technique is not amenable to industrial application since a second alignment step is necessary to place the layer on top of the previously patterned and annealed one. A very successful solution has been found with the deposition of a Ni/Au bilayer directly on top of the Ti/Al that addresses the oxidation issue with much success. ${ }^{6,16}$ The Ni layer is used to prevent rapid diffusion of $\mathrm{Au}$ into the multilayer, but the Ni itself has a very high work function and is a questionable choice for use in an ohmic contact to an $n$-type semiconductor. Pt has been used in the place of $\mathrm{Ni}$ to stop the rapid diffusion of Au into the multilayer, although it really offers no more favorable characteristics than the $\mathrm{Ni}$ that it replaces. A study of the Ti/Al/Pt/Au contact (to Al$\mathrm{GaN}$ ) revealed that its behavior is very similar to the contact containing $\mathrm{Ni}^{17}{ }^{17} \mathrm{~A} \mathrm{Ti} / \mathrm{Al} / \mathrm{Ti} / \mathrm{Au}$ structure that has been recently investigated shows some promise, since it removes the problematic Ni layer in favor of a second Ti layer. ${ }^{14}$ The researchers who developed this contact claim that the $\mathrm{Ti}$ and $\mathrm{Au}$ will form a robust, oxidation resistant layer at the surface, but this is unsubstantiated. The high mobility of the Au, when coupled with the incomplete ternary phase diagram of the $\mathrm{Ti}-\mathrm{Al}-\mathrm{Au}$ system, means that it is impossible to predict that the Au will remain near the film's surface rather than migrating to the metal/semiconductor interface.

Many of these contacts involve $\mathrm{Au}$ as the top layer. $\mathrm{Au}$ has dual characteristics as an excellent conductor and a noble metal, thus it seems a particularly good choice as an oxidation cap to maintain the contact's low sheet resistance following thermal treatment. Unfortunately, Au is not a very compatible material to these ohmic contact schemes, since it has a relatively high barrier height to $n$-GaN. ${ }^{18,19}$ It has been observed that a Au oxidation cap is not effective when deposited directly on the Ti/Al bilayer. ${ }^{20} \mathrm{Au}$ is not thermally stable on the Al layer, and it can subsequently diffuse easily to the interface to increase the specific contact resistance by increasing the barrier height at the interface. The Ti/Al/ $\mathrm{Ni} / \mathrm{Au}$ contact was the first viable contact system introduced, and it remains the benchmark against which all $n$-GaN ohmic contacts are measured. The group that suggested the Ti/Al/ $\mathrm{Ni} / \mathrm{Au}$ contact intended the $\mathrm{Ni}$ and $\mathrm{Au}$ to react to form a robust cap on top of the Ti/Al portion of the contact. ${ }^{6} \mathrm{Ni}$ has been found to form an even higher barrier on $n$-GaN than $\mathrm{Au},{ }^{18}$ thus it is a higher risk than the Au for increasing the contact resistance if it manages to migrate to the interface. Fan $e t$ al. considered the problem of high work function metals in the contact, as well as the fact that the $\mathrm{Ni}$ and $\mathrm{Al}$ were likely to react, when they decided to make the $\mathrm{Al}$ layer much thicker than what was common in Ti/Al contacts to that point. The thicker layer of $\mathrm{Al}$, well in excess of three times the thickness of the Ti layer, is intended to provide for reaction from both sides and keep the high work function metals away from the interface. Some of the excess Al can be consumed in the reaction with the $\mathrm{Ni}$, but the ample thickness should provide enough for the $\mathrm{Ti}-\mathrm{Al}$ reaction to occur as it does in the bilayer without significant changes. The optimum anneal for achieving the ideal compromise of low contact resistance and minimal interdiffusion seems to be a short period of $15-30 \mathrm{~s}$ at a temperature in excess of $900^{\circ} \mathrm{C}$. It should be noted that alloys that contain high work function elements might not offer the same problems to ohmic contact formation as the high work function elements by themselves. Ingerly et al. found that $\mathrm{NiAl}$ is in fact a very good ohmic contact to $n$-GaN. ${ }^{21}$ Diffusion of these materials to the interface, where they will likely be in an alloyed state, may not be significantly detrimental to the ultimate performance depending on the mechanism responsible for the ohmic nature of the contact. The complexities of the possible operative mechanisms that could determine the electrical performance in a mixed interface contact (that contains many phases in the metal/semiconductor interfacial region) make prediction very difficult. As a first step in design considerations, though, it is probably best to try to prevent their presence in the interfacial region due to the possibility of raising the barrier height.

High work function elemental migration in the Ti/Al/ $\mathrm{Ni} / \mathrm{Au}$ contact is revealed in two high-resolution transmission electron microscopy studies that were performed on this contact, albeit on slightly different substrates. Following a thermal treatment of $30 \mathrm{~s}$ at $900{ }^{\circ} \mathrm{C}$ in $\mathrm{N}_{2}$, Ruvimov et al. identified crystallites of $\mathrm{Ti}-\mathrm{N}$ and $\mathrm{Ti}-\mathrm{Al}$ alloys at the interface, but they were also able to detect small amounts of $\mathrm{Ni}$ and $\mathrm{Au}$ in this region. ${ }^{7}$ Bright et al. studied an identical contact structure deposited on an AlGaN substrate and annealed for $1 \mathrm{~min}$ at $900^{\circ} \mathrm{C}$ in Ar. They found that there were $\mathrm{Al}-\mathrm{Ti}$ crystallites at the interface that contained a significant amount of $\mathrm{Au}(25$ at. \%) as well as $\mathrm{Ni}-\mathrm{Al}$ and $\mathrm{Al}-\mathrm{Au}$ alloys present throughout the contact. ${ }^{22}$ It should be noted that the substrates used in Ruvimov's study were subjected to reactive ion etching (RIE) prior to the metal deposition. Ruvimov et al. suggested that the RIE treatment prior to film deposition could affect the reaction kinetics by significantly increasing the point defect density in the near surface region of the GaN. Such an effect has been observed in palladium silicide contacts that were deposited on RIE treated $\mathrm{Si}$ wafers, ${ }^{23}$ thus it is reasonable to assume that it could also happen in the nitride system. Without the RIE step, there would not be a large difference in the reactions between these two substrates since $\mathrm{GaN}$ and $\mathrm{AlGaN}$ form a continuous solid solution. The thermal stabilities would thus be only slightly affected by the difference in the composition of the $\mathrm{Al}_{x} \mathrm{Ga}_{1-x} \mathrm{~N}$ phase.

The $\mathrm{Ti} / \mathrm{Al} / \mathrm{Ni} / \mathrm{Au}$ contact addresses the oxidation problem of the Ti/Al contact, but the price for the solution is paid in device implementation. The anneal must be at very high temperature for a short period of time to prevent significant amounts of the high work function $\mathrm{Ni}$ and $\mathrm{Au}$ elements from diffusing to the interface. These special annealing conditions are not a large concern for many nitride-based devices, but in the case of laser diodes, ohmic contact must be made to both $n$ - and $p-\mathrm{GaN}$ in the same device. A significant advancement has been made in ohmic contact technology for $p$-GaN with the discovery that the specific contact resistance of the $\mathrm{Ni} / \mathrm{Au}$ contact improves significantly when annealed in an oxidizing atmosphere. ${ }^{24,25}$ When both the $n$ - and $p$-type ohmic contacts are present on the same device, either a multistep deposition and anneal procedure must be employed (if possible), or a compromised annealing recipe must be determined that will not fully optimize either contact. An $n$-GaN contact that can 
achieve near optimum performance after a heat treatment of several minutes at a lower temperature and in an oxidizing ambient would be a tremendous step forward for these devices.

We have used a $\mathrm{TiAl}_{3}$ layer as a thermally stable oxidation cap for the Ti/Al contact. This intermetallic cap has some attractive features that have been previously hard to find in the elemental and multilayered elemental caps. According to the bulk phase diagram, $\mathrm{TiAl}_{3}$ is in equilibrium with $\mathrm{Al}$, thus its presence in the contact structure will not adversely affect the reaction between the $\mathrm{Ti}$ and $\mathrm{Al}$ layers. Furthermore, $\mathrm{TiAl}_{3}$ should be an excellent oxidation cap due to the formation of a very thin but continuous protective $\mathrm{Al}_{2} \mathrm{O}_{3}$ layer at the surface. ${ }^{26,27}$ The advantages of a thermally stable cap are obvious, since no alteration to a previously optimized bilayer contact would be necessary. Thin film studies and model calculations of Ti/Al multilayers have shown that $\mathrm{TiAl}_{3}$ is always the first to form, but the final composition of the bulk depends on the overall composition of the structure. ${ }^{28,29}$ The observations made in these studies suggest that whenever the Al layer is three times or more than the thickness of the $\mathrm{Ti}$ in the bilayer, $\mathrm{TiAl}_{3}$ will remain the stable phase after the anneal. Since the $\mathrm{TiAl}_{3}$ phase is not expected to interfere with the $\mathrm{Ti}-\mathrm{Al}$ reaction during thermal treatment, we intend to verify that it will also be suitable for designing a contact that can be optimized at significantly lower temperatures than those common to the Ti/Al/Ni/Au contact.

\section{EXPERIMENTAL PROCEDURE}

The $n$-GaN substrate used in this study was grown by metalorganic chemical vapor deposition on a $c$-plane sapphire substrate. It is intentionally doped with $\mathrm{Si}$, and the carrier concentration was determined by Hall measurement to be $2-4 \times 10^{18} \mathrm{~cm}^{-3}$. The $\mathrm{Ti}(35 \mathrm{~nm}) / \mathrm{Al}(115 \mathrm{~nm}) / \mathrm{TiAl}_{3}(50$ $\mathrm{nm}$ ) structures were deposited by dc magnetron sputtering of 2 in. targets with a background pressure of less than 2 $\times 10^{-7}$ Torr. Ti and Al targets were purchased commercially and have a purity of $99.99 \%$ and $99.998 \%$, respectively. The $\mathrm{TiAl}_{3}$ compound target was arc melted in our laboratory under ultrahigh purity (UHP) Ar of $99.995 \%$ purity, and we used starting materials consisting of Ti crystal $(99.998 \%$ purity, metals basis) and Al shot (99.999\% purity, metals basis). The target composition was checked by electron probe microanalysis with a Cameca SX-90 electron microprobe, and the alloy was found to be $74 \pm 6$ at. $\%$ Al. There was an $8 \%$ uncertainty in the microprobe composition due to the difficulties with the Al standard, but the nominal concentration is close to $\mathrm{TiAl}_{3}$. A Ti(20 nm)/Al(100 nm)/Ni(20 nm)/Au(80 $\mathrm{nm}$ ) contact, which is a structure that has been previously studied, ${ }^{16}$ was fabricated on the same substrate as a standard for comparison and a control for the contact's performance. We chose to use the same structure as that of Papanicolaou et al. due to the fact that it closely matched the Ti:Al layer thickness ratio of our contact. The $\mathrm{Ti} / \mathrm{Al} / \mathrm{Ni} / \mathrm{Au}$ multilayer was deposited via $e$-beam evaporation with a base pressure of $4 \times 10^{-7}$ Torr.
TABLE I. Best specific contact resistances obtained for Ti/Al, Ti/Al/TiAl ${ }_{3}$, and $\mathrm{Ti} / \mathrm{Al} / \mathrm{Ni} / \mathrm{Au}$ contacts processed on the same $n-\mathrm{GaN}$ substrates. All contacts were rapid thermal annealed in an oxygen-gettered UHP Ar ambient

\begin{tabular}{lccc}
\hline \hline & \multicolumn{3}{c}{ Contact } \\
\cline { 2 - 4 } & $\begin{array}{c}\mathrm{Ti} / \mathrm{Al} \\
\text { Annealing condition }\end{array}$ & $\begin{array}{c}\mathrm{Ti} / \mathrm{Al} / \mathrm{TiAl}{ }_{3} \\
700{ }^{\circ} \mathrm{C} / 1 \mathrm{~min}\end{array}$ & $\begin{array}{c}\mathrm{Ti} / \mathrm{Al} / \mathrm{Ni} / \mathrm{Au} \\
900{ }^{\circ} \mathrm{C} / 15 \mathrm{~s}\end{array}$ \\
\hline$\rho_{c}\left(\Omega \mathrm{cm}^{2}\right)$ & $3.1 \times 10^{-5}$ & $2.1 \times 10^{-5}$ & $1.8 \times 10^{-5}$ \\
\hline \hline
\end{tabular}

All substrates were degreased in warm, ultrasonically agitated acetone and methanol. They were then subjected to a two step etching procedure developed earlier ${ }^{11}$ that consisted of a $5 \mathrm{~s}$ dip in $\mathrm{H}_{2} \mathrm{SO}_{4}: \mathrm{H}_{3} \mathrm{PO}_{4}$ : $\mathrm{DI} \mathrm{H}_{2} \mathrm{O}(1: 1: 2)$ followed by a rinse and a 4 min dip in $\mathrm{HCl}: \mathrm{DI} \mathrm{H}_{2} \mathrm{O}(1: 1: 2)$ before photolithographic patterning. The patterned substrates were dipped for $25 \mathrm{~s}$ in $\mathrm{HCl}: \mathrm{DI} \mathrm{H}_{2} \mathrm{O}(1: 1: 4)$ immediately prior to entering them in their respective deposition chambers. Circular transmission line patterns were used to facilitate the electrical measurements. Rapid thermal processing was performed in an AG Associates Mini-Pulse RTA, and three annealing ambients were used in this study: UHP Ar that was passed through an oxygen-gettering tube, ordinary Ar, and air (no purge gas). The specific contact resistivities that are measured for increasing periods of annealing time were all taken on one specimen for each contact structure. The annealing time is the result of the total accumulated time at the process temperature and does not include the ramp up or cool down phases of each run. Long term thermal aging was performed in a box furnace in an air ambient on previously rapid thermal anneal-treated samples. All of the data points shown in the figures are the mean value of three or more measurements on different areas of the specimen. The error bars are the standard deviation of the mean for the specific contact resistances that were collected.

\section{RESULTS AND DISCUSSION}

To assess the quality of each of the contacts, they were annealed at close to their optimum conditions in an ambient that was carefully controlled for oxygen. Many groups have used $\mathrm{Ti} / \mathrm{Al} / \mathrm{Ni} / \mathrm{Au}$ contacts with very good success, and the most successful annealing recipes usually consist of a short run to a temperature in excess of $900{ }^{\circ} \mathrm{C}$. We found that our $\mathrm{Ti} / \mathrm{Al} / \mathrm{Ni} / \mathrm{Au}$ contact achieved a $\rho_{c}$ of $1.8 \times 10^{-5} \Omega \mathrm{cm}^{2}$ following a $15 \mathrm{~s}$ anneal at $900{ }^{\circ} \mathrm{C}$ in flowing, oxygen-gettered UHP Ar. We have performed extensive experiments on Ti/Al contacts in the past, and this value is nearly a factor of 2 better than what we can commonly achieve with the uncapped bilayer contact on this particular substrate. We have found, though, that our bilayer Ti/Al contacts are optimized at a much lower temperature of about $600{ }^{\circ} \mathrm{C}$ for $1 \mathrm{~min}$. The $\mathrm{TiAl}_{3}$-capped Ti/Al contact was found to have a lowest $\rho_{c}$ of $2.1 \times 10^{-5} \Omega \mathrm{cm}^{2}$ following $1 \mathrm{~min}$ at $700{ }^{\circ} \mathrm{C}$ in flowing, oxygen-gettered UHP Ar. Table I shows the best values obtained for both capped contacts in comparison with a standard uncapped $\mathrm{Ti} / \mathrm{Al}$ bilayer contact processed on the same substrate. It can be seen in Table I that the $\mathrm{Ti} / \mathrm{Al} / \mathrm{TiAl}_{3}$ contact seems to shift the optimization temperature higher, but 


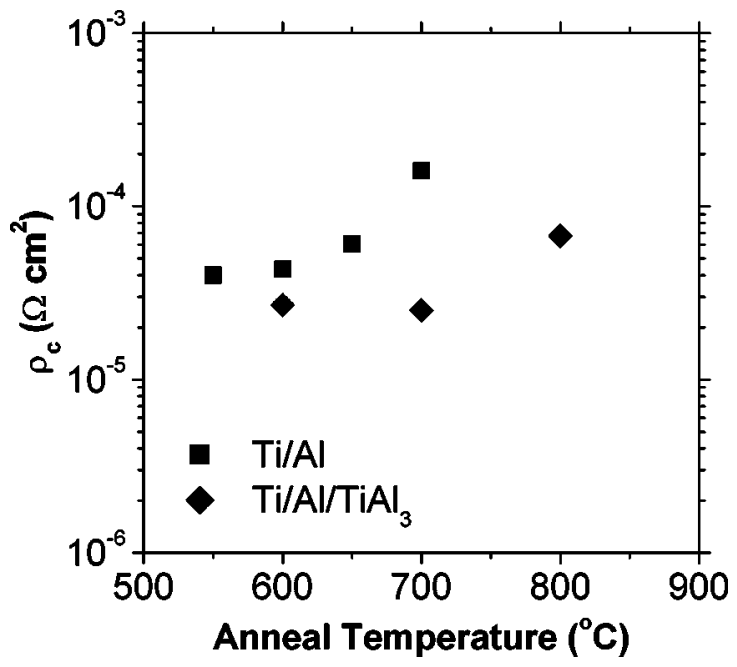

FIG. 1. Specific contact resistances of $\mathrm{Ti} / \mathrm{Al}$ and $\mathrm{Ti} / \mathrm{Al} / \mathrm{TiAl}_{3}$ contacts processed on the same $n$-GaN substrate. Both contacts were rapid thermal annealed in oxygen-gettered UHP Ar.

this is most likely due to the fact that the uncapped Ti/Al bilayer begins to degrade as the annealing temperature increases. Figure 1 shows the specific contact resistances of a $\mathrm{TiAl}_{3}$-capped and an uncapped Ti/Al contact resulting from different annealing treatments (in oxygen-gettered UHP Ar). The two contacts show very similar $\rho_{c}$ values at the lower temperatures, but the uncapped contact begins to degrade very quickly while the capped contact remains more stable at the higher processing temperatures. Following a $700^{\circ} \mathrm{C}$ anneal, the capped contact's specific contact resistance is nearly 1 full order of magnitude lower than that of the uncapped contact. It is certainly expected that the $\rho_{c}$ values of the capped and uncapped Ti/Al contact should be very similar at the lower temperatures, because the $\mathrm{TiAl}_{3}$ cap should not interfere with the mechanism operative in the original bilayer.

Since the $\mathrm{TiAl}_{3}$ cap for the Ti/Al contact is intended to protect the bilayer from oxidation, we annealed it in two ambients containing increasing levels of oxygen, namely ordinary $99.9 \%$ pure $\mathrm{Ar}$ and air. The $\mathrm{Ti} / \mathrm{Al} / \mathrm{Ni} / \mathrm{Au}$ contact is used as an experimental control to qualify the performance of the $\mathrm{TiAl}_{3}$-capped contact, so they were both annealed at the same temperature of $600^{\circ} \mathrm{C}$ in identical ambients. First, each contact was annealed at $600^{\circ} \mathrm{C}$ in ordinary Ar, where no special lengths were taken to purify the Ar of oxygen. The results of these annealing treatments are shown in Fig. 2. Both contacts can be seen to improve slightly between 1 and $5 \mathrm{~min}$, but the $\mathrm{TiAl}_{3}$-capped contact clearly performs better at this temperature, since its $\rho_{c}$ value eventually stabilizes at approximately $1.3 \times 10^{-5} \Omega \mathrm{cm}^{2}$ after a total time of $10 \mathrm{~min}$ at the process temperature. This is a factor of 10 lower than the best value achieved by the Ti/Al/Ni/Au contact under these conditions. The Ti/Al/ $\mathrm{TiAl}_{3}$ contact was annealed in flowing, oxygen-gettered UHP Ar for comparison (results not shown), and the minimum $\rho_{c}$ under these conditions was found to be $1.5 \times 10^{-5} \Omega \mathrm{cm}^{2}$. This performance is almost identical to that found in the ordinary Ar ambient with the higher oxygen content. The effect of the $\mathrm{TiAl}_{3}$ oxygen cap is

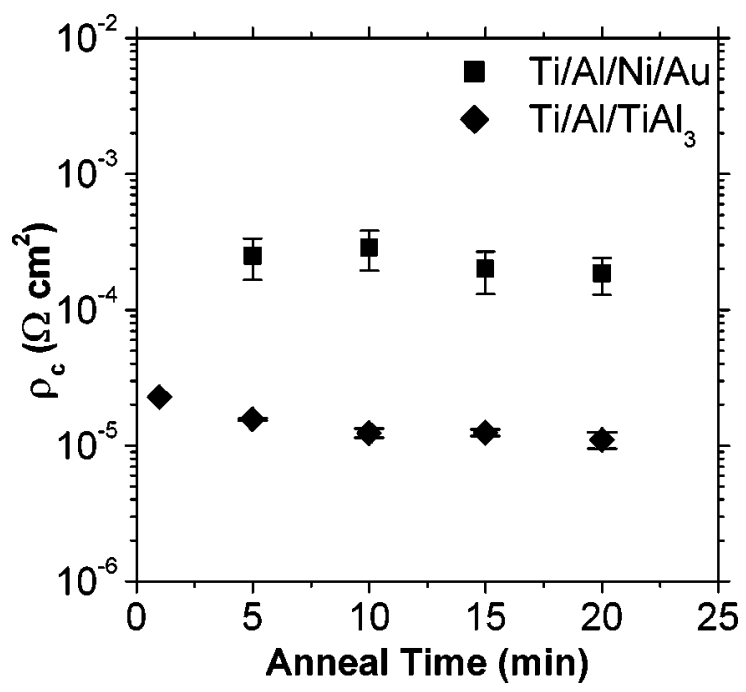

FIG. 2. Specific contact resistances of $\mathrm{Ti} / \mathrm{Al} / \mathrm{TiAl}_{3}$ and $\mathrm{Ti} / \mathrm{Al} / \mathrm{Ni} / \mathrm{Au}$ contacts as a function of total accumulated time at $600^{\circ} \mathrm{C}$ in ordinary $\mathrm{Ar}$.

favorable considering that we have found the electrical performance of uncapped Ti/Al to be significantly affected by the oxygen content of the annealing ambient. ${ }^{11}$

The ultimate test of an oxidation cap's effectiveness is obviously to anneal it in a very oxidizing atmosphere. For this test, we chose to anneal each contact in air by not introducing any purge gas into the RTA chamber once the door was closed, and the results are summarized in Fig. 3. Air was used because it has been found to be as effective as pure $\mathrm{O}_{2}$ when used as the purge gas when processing ohmic contacts to $p$-GaN. ${ }^{25}$ We found that the performance of the Ti/Al/ $\mathrm{Ni} / \mathrm{Au}$ contact was very similar to that obtained after it was annealed in the ordinary $\mathrm{Ar}$ ambient. The Ti/Al/TiAl ${ }_{3}$ contact, similarly, was found to achieve a $\rho_{c}$ of $1.1 \times 10^{-5}$ $\Omega \mathrm{cm}^{2}$ following $5 \mathrm{~min}$ at $600^{\circ} \mathrm{C}$. This value is, again, almost identical to that achieved in the other two annealing ambients. This is a very positive result, indicating the effec-

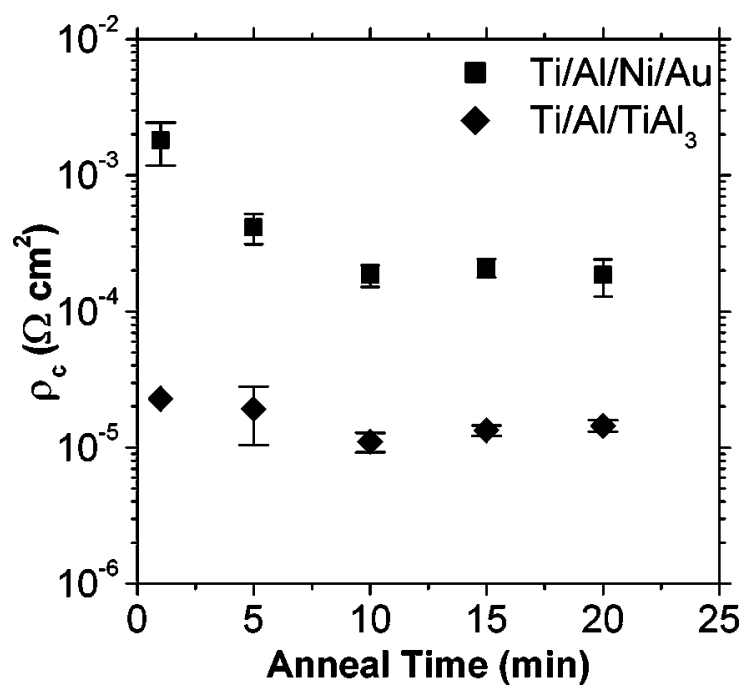

FIG. 3. Specific contact resistances of $\mathrm{Ti} / \mathrm{Al} / \mathrm{TiAl}_{3}$ and $\mathrm{Ti} / \mathrm{Al} / \mathrm{Ni} / \mathrm{Au}$ contacts as a function of total accumulated time at $600{ }^{\circ} \mathrm{C}$ in air. 




FIG. 4. Specific contact resistances of $\mathrm{Ti} / \mathrm{Al} / \mathrm{TiAl}_{3}$ and $\mathrm{Ti} / \mathrm{Al} / \mathrm{Ni} / \mathrm{Au}$ contacts as a function of total accumulated time at $350{ }^{\circ} \mathrm{C}$ in air. The Ti/Al/TiAl contact was previously annealed for a total of $20 \mathrm{~min}$ at $600{ }^{\circ} \mathrm{C}$ and stored at room temperature for more than 30 days. The Ti/Al/Ni/Au contact was previously annealed for $15 \mathrm{~s}$ at $900{ }^{\circ} \mathrm{C}$ and stored at room temperature for more than 30 days.

tiveness of the oxidation cap, and it proves that the performance of the $\mathrm{Ti} / \mathrm{Al} / \mathrm{TiAl} \mathrm{A}_{3}$ is insensitive to the amount of oxygen in its annealing atmosphere.

Longer-term thermal aging was performed to see if the contacts experienced any degradation in their performance over time. The $\mathrm{Ti} / \mathrm{Al} / \mathrm{TiAl}_{3}$ sample that was annealed at $600{ }^{\circ} \mathrm{C}$ for a total of $20 \mathrm{~min}$ in the air ambient was measured again after storage at room temperature (RT) in air more than 30 days. The $\rho_{c}$ value that was measured was $1.3 \times 10^{-5}$ $\Omega \mathrm{cm}^{2}$, which had not significantly changed from the value measured immediately following the anneal. Likewise, a Ti/ $\mathrm{Al} / \mathrm{Ni} / \mathrm{Au}$ sample that was annealed at $900^{\circ} \mathrm{C}$ in the UHP oxygen-gettered Ar was measured again after storage at RT in air for the same amount of time. The $\rho_{c}$ value that was measured was $3.1 \times 10^{-5} \Omega \mathrm{cm}^{2}$, which was also not significantly different than the value measured immediately following the anneal. It should be noted this $\mathrm{Ti} / \mathrm{Al} / \mathrm{Ni} / \mathrm{Au}$ specimen was different than the one reported previously for the $900{ }^{\circ} \mathrm{C} / 15 \mathrm{~s}$ anneal, which was done for experimental reasons. Both contacts were placed in a box furnace and annealed in air at $350{ }^{\circ} \mathrm{C}$. No significant degradation in electrical performance was observed, as can be seen in Fig. 4, but it should be noted that it took more work to get the reading from the $\mathrm{TiAl}_{3}$-capped contact after the longest aging step. This is presumably due to a slightly thicker surface oxide than had been formed in the previous experiments, and the extra effort was to make good contact with the probe tips with the intact metal underneath. The formation of additional oxide could be the result of other $\mathrm{Ti}-\mathrm{Al}$ phases in the cap, resulting from slight nonstoichiometry of the metal composition on the Ti-rich side of $\mathrm{TiAl}_{3} \cdot{ }^{26}$ Small amounts of other $\mathrm{Ti}-\mathrm{Al}$ phases, that are more susceptible to oxidation, could lead to degradation of the contact, although we do not know if this is the case for our contact. The Ti/Al/Ni/Au contact's performance is known by other researchers to remain stable over time, and our $\mathrm{TiAl}_{3}$-capped contact can be seen to per- form likewise. This suggests that the mechanism responsible for our contact's success is robust enough for device implementation. At first glance, this result seems almost trivial, but other contacts have been found to degrade over time during storage, which indicates environmental factors that can influence the contact's stability. ${ }^{30,31}$ The stability of this contact at higher temperatures in an air environment is also potentially useful for the implementation in a device. Devices that are operated under high current conditions, such as laser diodes, have the potential to generate a lot of heat. If such a device is operated in an air ambient, it would be particularly susceptible to a shortened lifetime if the contacts cannot withstand these conditions. The thermal stability of the $\mathrm{Ti} / \mathrm{Al} / \mathrm{TiAl}_{3}$ contact could successfully address this issue.

Earlier work performed by our group indicated that the amount of oxygen in the annealing ambient has a profound effect on the performance of the Ti/Al contact. It should be reiterated that the degradation of the contact's performance after more extreme annealing conditions is not always due to an increase in the resistance from the metal/semiconductor interface, even though the measurement of the specific contact resistance parameter is usually where such degradation is observed. Actually, the increase in the measured $\rho_{c}$ is often the result of an increase in the metal's sheet resistance $R_{m}$ due to the convolution of this parameter in the measurement of $\rho_{c}$, as has been shown by other groups. ${ }^{12,22,32}$ The transmission line technique and the modified circular transmission line technique, where the latter is used in this study, both calculate $\rho_{c}$ from the $R_{m}$ value that is obtained from a least squares fit to the experimental data. Since the relationship between $\rho_{c}$ and $R_{m}$ is linear, a significant increase in the metal sheet resistance, such as is likely to occur if there is significant oxidation of the metal, will show up as an increase in the specific contact resistance. ${ }^{32,33}$

Depositing the $\mathrm{TiAl}_{3}$ cap virtually eliminated the degradation of the measured $\rho_{c}$ as the oxygen level increased to around $20 \%$ (air). We attribute this to the ability of $\mathrm{Ti}-\mathrm{Al}$ alloys to form a thin protective aluminum oxide layer at the surface of the metal film, thus protecting the bulk of the film from further oxidation. Even though pure Al can form a protective oxide layer, the situation in the bilayer case is not as favorable as that with the alloy cap. When the bilayer is annealed at temperatures in excess of the melting point of $\mathrm{Al}$ $\left(660^{\circ} \mathrm{C}\right.$ for bulk $\mathrm{Al}$ ), balling of this layer can cause the $\mathrm{Al}_{2} \mathrm{O}_{3}$ layer that forms to be discontinuous. Such a layer will not offer significant protection. Also, microstructural studies of bilayer contacts have shown that the oxide layer on $\mathrm{Al}$ can be in excess of $25 \mu \mathrm{m}$ thick following thermal treatment, which is a significant amount of the overall thickness of the metal film. ${ }^{34}$ The $\mathrm{TiAl}_{3}$ capping film, though, is refractory in nature and will not degrade until temperatures exceed $1300^{\circ} \mathrm{C}$, thus no significant change in its morphology is expected at the annealing temperatures common to the processing of these contacts. It is particularly fortuitous that the $\mathrm{TiAl}_{3}$ phase is thermally stable on the top of the Ti/Al contact, because this particular $\mathrm{Ti}-\mathrm{Al}$ intermetallic is the only one known to form a stable and continuous protective $\mathrm{Al}_{2} \mathrm{O}_{3}$ oxide scale, which is attributed to its high $\mathrm{Al}$ content. ${ }^{26,27}$ For these reasons, the metal film conductivity of the capped con- 


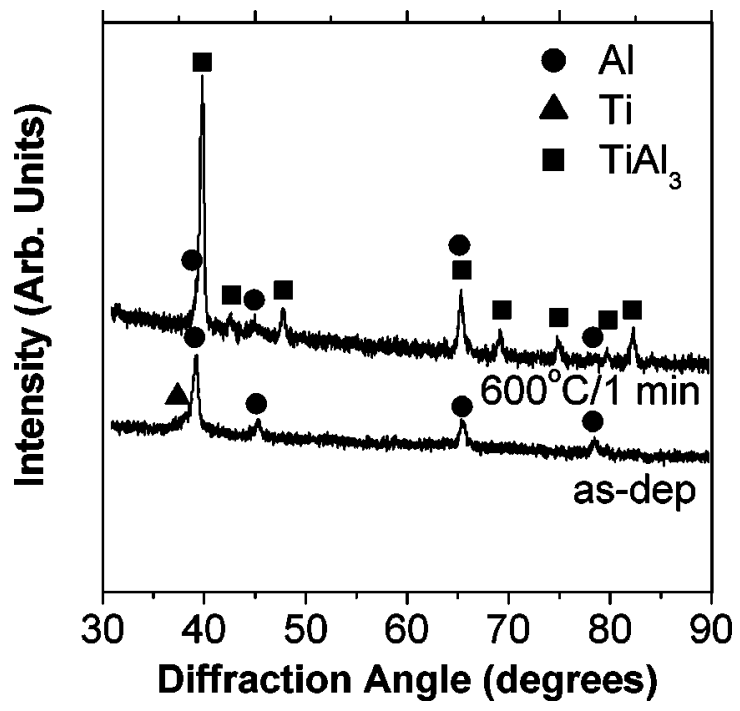

FIG. 5. GAXRD of an annealed Ti $(35 \mathrm{~nm}) / \mathrm{Al}(115 \mathrm{~nm})$ bilayer deposited on GaN following two different annealing treatments. An incident angle of $1^{\circ}$ was used. Following an anneal at $600^{\circ} \mathrm{C}$ for $1 \mathrm{~min}$, the structure has clearly transformed to the $\mathrm{DO}_{22}$ phase of $\mathrm{TiAl}_{3}$ with some excess $\mathrm{Al}$ remaining.

tact is not as adversely affected. The glancing angle $\mathrm{x}$-ray diffraction (GAXRD) of our uncapped Ti/Al structure revealed that the bilayered structure reacts to become predominantly the $\mathrm{DO}_{22} \mathrm{TiAl}_{3}$ phase with some excess $\mathrm{Al}$ remaining following a $1 \mathrm{~min}$ anneal at $600{ }^{\circ} \mathrm{C}$ in UHP oxygen-gettered $\mathrm{Ar}$, as shown in Fig. 5. Kwak et al. found that a Ti/Al structure with the same nominal layer thickness ratio also was found to be $\mathrm{TiAl}_{3}$ following a $600{ }^{\circ} \mathrm{C}$ anneal. ${ }^{12}$ This suggests that a $\mathrm{TiAl}_{3}$ layer deposited on top is actually a perfect cap for this contact structure, because it can allow the Ti and the $\mathrm{Al}$ to react to completion without intervening due to the thermodynamic stability of the $\mathrm{TiAl}_{3} / \mathrm{Al}$ interface. The presence of excess $\mathrm{Al}$ would not be expected to be seriously detrimental to contact performance, since it would not cause any further reaction.

The stability on $\mathrm{Al}$ is also an attractive attribute for the possible application of the $\mathrm{TiAl}_{3}$ cap, because it is not uncommon to find that different research groups have settled on slightly different layer thickness ratios in their bilayer structures that seem to be optimized for their process and substrate. ${ }^{11}$ All of the recipes involve $\mathrm{Al}$ as the topmost layer in the $\mathrm{Ti} / \mathrm{Al}$ structure, so the $\mathrm{TiAl}_{3}$ cap should be compatible with all of them without altering the critical features of the reaction, as discussed previously. The $\mathrm{TiAl}_{3}$ would not be expected to remain thermally stable if deposited on a structure where the Ti:Al layer thickness ratio is significantly less than 1:3, since all of the $\mathrm{Al}$ will be consumed in the bilayer reaction and residual $\mathrm{Ti}$ will remain. In this case, other titanium aluminides are expected to form based on the bulk phase diagram.

\section{CONCLUSIONS}

We have shown that $\mathrm{TiAl}_{3}$ is a very effective oxidation cap for Ti/Al ohmic contacts to $n-\mathrm{GaN}$. The Ti/Al/TiAl ${ }_{3}$ contacts were optimized at a significantly lower temperature than $\mathrm{Ti} / \mathrm{Al} / \mathrm{Ni} / \mathrm{Au}$ contacts that were processed on the same substrates, but the ultimate specific contact resistance was virtually the same for both structures. Furthermore, the $\mathrm{Ti} / \mathrm{Al} / \mathrm{TiAl}_{3}$ contacts were found to be very insensitive to the amount of oxygen in the annealing ambient, as they achieved the same specific contact resistance when annealed in oxygen-gettered UHP Ar, ordinary Ar, and air. This suggests that the $\mathrm{Ti} / \mathrm{Al} / \mathrm{TiAl}_{3}$ contact is a potential candidate for implementation in devices that require both $n$ - and $p$-GaN contacts on the same wafer, since it can achieve near optimal performance in an oxidizing anneal at roughly the same temperature as that common for $\mathrm{Ni} / \mathrm{Au}$ contacts to $p$-GaN. Additionally, the $\mathrm{TiAl}_{3}$ cap's stability on $\mathrm{Al}$ allows this oxidation cap to be used on almost any existing Ti/Al contact structure without changing the layer thickness ratio. The $\mathrm{TiAl}_{3}$ layer will not interfere in the reaction of the other two key layers.

\section{ACKNOWLEDGMENTS}

The authors would like to thank G. Jiang for her work to obtain the GAXRD diffraction pattern of our Ti/Al bilayer, as well as P. F. Ladwig for his critical review of this article. The $n$-GaN substrates were supplied by T. Takeuchi of Agilent Technologies, Inc. This work has been funded under the NSF Grant No. DMR-9902885.

${ }^{1}$ H. Morkoc, S. Strite, G. B. Gao, B. Sverdlov, and M. Burns, J. Appl. Phys. 76, 1363 (1994)

${ }^{2}$ S. Nakamura, M. Senoh, N. Iwasa, and S. Nagahama, Jpn. J. Appl. Phys., Part 2 34, L797 (1995).

${ }^{3}$ S. J. Pearton, J. C. Zolper, and R. J. Shul, J. Appl. Phys. 86, 1 (1999).

${ }^{4}$ O. Aktas, Z. F. Fan, S. N. Mohammad, A. E. Botchkarev, and H. Morkoc, Appl. Phys. Lett. 69, 3872 (1996).

${ }^{5}$ S. C. Binari, K. Doverspike, G. Kelner, H. B. Dietrich, and A. E. Wikenden, Solid-State Electron. 41, 177 (1997).

${ }^{6}$ Z. Fan, S. N. Mohammad, W. Kim, O. Aktas, A. E. Botchkarev, and H. Morkoc, Appl. Phys. Lett. 68, 1672 (1996).

${ }^{7}$ S. Ruvimov et al., Appl. Phys. Lett. 69, 1556 (1996).

${ }^{8}$ B. P. Luther, S. E. Moheny, T. N. Jackson, M. Asif Khan, Q. Chen, and J. W. Yang, Appl. Phys. Lett. 70, 57 (1997).

${ }^{9}$ B. P. Luther, J. M. DeLucca, S. E. Mohney, and R. F. Karlicek, Jr., Appl. Phys. Lett. 71, 3859 (1997)

${ }^{10}$ P. Ruterana, G. Nouet, Th. Kehagias, Ph. Komninou, Th. Karakostas, M. A. di Forte Poisson, F. Huet, and H. Morkoc, Phys. Status Solidi A 176, 767 (1999).

${ }^{11}$ C. M. Pelto, Y. A. Chang, Y. Chen, and R. S. Williams, Solid-State Electron. 45, 1597 (2001).

${ }^{12}$ J. S. Kwak, S. E. Mohney, J.-Y. Lin, and R. S. Kern, Semicond. Sci. Technol. 15, 756 (2000).

${ }^{13}$ M. E. Lin, Z. Ma, F. Y. Huang, Z. F. Fan, L. H. Allen, and H. Morkoc, Appl. Phys. Lett. 64, 1003 (1994).

${ }^{14}$ D.-F. Wang, F. Shiwei, C. Lu, A. Motayed, M. Jah, S. N. Mohammad, K. A. Jones, and L. Salamanca-Riba, J. Appl. Phys. 89, 6214 (2001).

${ }^{15}$ Y. Wu, W. Jiang, B. Keller, D. Kapolnek, S. DenBaars, and U. Mishra, Topical Workshop on III-V Nitrides Processing, Nagoya, Japan, 1995.

${ }^{16}$ N. A. Papanicolaou, M. V. Rao, J. Jittereder, and W. T. Anderson, J. Vac. Sci. Technol. B 19, 261 (2001).

${ }^{17}$ S. J. Cai, R. Li, Y. L. Chen, L. Wong, W. G. Wu, S. G. Thomas, and K. L. Wang, Electron. Lett. 34, 2354 (1998).

${ }^{18}$ A. C. Schmitz, A. T. Ping, M. Asif Khan, Q. Chen, J. W. Yang, and I. Adesida, J. Electron. Mater. 27, 255 (1998).

${ }^{19}$ S. K. Noh and P. Bhattacharya, Appl. Phys. Lett. 78, 3642 (2001).

${ }^{20}$ C.-T. Lee and H.-W. Kao, Appl. Phys. Lett. 76, 2364 (2000).

${ }^{21}$ D. B. Ingerly, Y. Chen, R. S. Williams, T. Takeuchi, and Y. A. Chang, Appl. Phys. Lett. 77, 382 (2000).

${ }^{22}$ A. N. Bright, P. J. Thomas, M. Weyland, D. M. Tricker, and C. J. Humphreys, J. Appl. Phys. 89, 3143 (2001). 
${ }^{23}$ A. Climent and S. J. Fonash, J. Appl. Phys. 56, 1063 (1984)

${ }^{24}$ J.-K. Ho, C.-S. Jong, C. C. Chiu, C.-N. Huang, C.-Y. Chen, and K.-K. Shih, Appl. Phys. Lett. 74, 1275 (1999).

${ }^{25}$ Y. Koide, T. Maeda, T. Kawakami, S. Fujita, T. Uemura, N. Shibata, and M. Murakami, J. Electron. Mater. 28, 341 (1999).

${ }^{26}$ J. L. Smialek and D. L. Humphrey, Scr. Metall. Mater. 26, 1763 (1992).

${ }^{27}$ R. Ga. Reddy, X. Wen, and I. C. I. Okafor, Metall. Mater. Trans. A 31A, 3023 (2000).

${ }^{28}$ F. J. J. van Loo and G. D. Rieck, Acta Metall. 21, 61 (1973).

${ }^{29}$ C. -P. Chen and Y. A. Chang, in Diffusion in Ordered Alloys, edited by B. Fultz, R. W. Cahn, and D. Gupta, (The Minerals, Metals, and Materials
Society, Warrendale, PA, 1993), pp. 169-184.

${ }^{30}$ M. Suzuki, T. Kawakami, T. Arai, S. Kobayashi, Y. Koide, T. Uemura, N. Shibata, and M. Murakami, Appl. Phys. Lett. 74, 275 (1999).

${ }^{31}$ E. D. Readinger, B. P. Luther, S. E. Mohney, and E. L. Piner, J. Appl. Phys. 89, 7983 (2001).

${ }^{32}$ B. P. Luther, S. E. Mohney, J. M. DeLucca, and R. F. Karlicek, J. Electron. Mater. 27, 196 (1998).

${ }^{33}$ G. S. Marlow and M. B. Das, Solid-State Electron. 25, 91 (1982).

${ }^{34}$ A. N. Bright, D. M. Tricker, C. J. Humphreys, and R. Davies, J. Electron. Mater. 30, L13 (2001). 